\title{
A amizade no foco da notícia: relacionamentos interpessoais na imprensa brasileira
}

Luciana Moura e Agnaldo Garcia

\section{Resumo}

Este trabalho analisou como a amizade se insere no cotidiano dos brasileiros a partir da observação das notícias que foram veiculadas em um jornal de grande circulação no país entre 2008 e 2010. A amostra foi formada por 1695 matérias jornalísticas que apresentaram a palavra amizade como parte de seus títulos e/ ou textos. A análise identificou 11 categorias nas quais as matérias foram classificadas, e os resultados indicaram que a amizade é vista como uma forma de relacionamento que proporciona emoções positivas, realizações pessoais, bemestar, melhora 0 desempenho individual, traz maior satisfação pessoal e garante a concessão de benefícios mútuos. As matérias analisadas também associaram, em vários aspectos, os relacionamentos típicos de amizade às relações românticas.

\section{Palavras-Chave}

Noticiário. Imprensa. Relacionamentos interpessoais. Amizade. Matérias jornalísticas.

Luciana Moura | lucianatmoura@gmail.com Doutora em Psicologia pela Universidade Federal do Espírito Santo - UFES. Professora do curso de Jornalismo da Universidade Vila Velha - UVV.

Agnaldo Garcia I agnaldo.garcia@uol.com.br Doutor em Psicologia pela Universidade de São Paulo - USP. Professor do curso de Psicologia da Universidade Federal do Espírito Santo - UFES.

\section{Considerações Iniciais}

0s relacionamentos interpessoais são temas muito presentes na imprensa em geral. Programas de variedade e noticiários abordam com abundância aspectos das relações humanas em suas reportagens, e isso porque há uma percepção clara de que esse tipo de assunto aumenta a audiência. A imprensa também é responsável por apresentar ao público, mesmo que superficialmente, alguns estudos realizados pela área da ciência que investiga os relacionamentos interpessoais, mas isso se dá em periódicos especializados. No entanto, percebe-se que a grande ênfase na divulgação de informações sobre relacionamentos pela imprensa de massa utiliza a exploração de abordagens do tipo "autoajuda", a partir da apresentação de "modelos" de relacionamentos e das famosas "dicas" de como conviver melhor (SCHWERTNER, 2010). Embora esse tipo de saber não possa ser considerado científico, a sua grande procura e aceitação por parte do público faz perceber que, de fato, os relacionamentos interpessoais estão no centro da vida das pessoas, tornando-se temas de preocupações cotidianas 
e despertando interesses em torno de maiores conhecimento e informação.

Por outro lado, as investigações que visam sistematizar como a imprensa aborda e de que modo apresenta as relações interpessoais são raras, talvez por ser uma área de estudo ainda muito recente, especialmente no Brasil, ou ainda pela falta de pesquisadores que transitem entre os limites interdisciplinares da comunicação e dos estudos sobre relações humanas. Alguns trabalhos que são encontrados discutem especificamente 0 tratamento dado por revistas femininas segmentadas ao estudo das relações românticas (CASALI, 2006); buscam uma abordagem mais histórica e generalista do tema (MARTINS, 2008) ou abordam as relações interpessoais a partir de outros contextos (COUTO e MENANDRO, 2003).

Não foram localizados dados que registrem ou analisem o tratamento dado pela imprensa brasileira ao tema amizade.

\section{A amizade se caracteriza por uma forma de} relacionamento espontâneo, que desfruta de uma liberdade que não se compara aos tipos mais formais de relação e tem características próprias (BELL, 1981; FEHR, 1996). Aristóteles já estudava a amizade, porém a psicologia passou a se preocupar com esse tema há não mais que 20 anos (GARCIA, 2005). 0s amigos são lembrados em momentos de grande necessidade tanto quanto nas maiores alegrias. As pessoas se comportam de forma diferente com amigos e não amigos, demonstrando com os primeiros mais afetividade, reciprocidade, intimidade, atividade social e maior disposição para resolver conflitos (ERBOLATO, 2001). Além disso, o desenvolvimento de relações de amizade proporciona bem-estar, estabilidade e autoconfiança (ARGYLE, 2001).

0 objetivo geral deste trabalho é analisar como a amizade se insere no cotidiano dos brasileiros, a partir da observação das notícias que são veiculadas em um jornal de grande circulação no país. Na medida em que a imprensa, especialmente a partir dos periódicos diários, se propõe a ser um instrumento de registro da sociedade, avaliar 0 tratamento dado ao tema amizade pode ajudar a entender o papel que esse tipo de relacionamento ocupa na vida das pessoas. Dada a penetração da imprensa na vida cotidiana, entender como são apresentados determinados temas pode ajudar a compreender como as pessoas refletem e se posicionam frente a eles. Muitos assuntos, tidos como mais complexos, são, de certa forma, "traduzidos" e explicados para a grande massa de leitores a partir dos textos jornalísticos, sejam impressos ou eletrônicos. Daí depreende-se que a imprensa pode assumir o lugar do suposto saber das massas, e reconhecer em que nível se dá esse processo no que se concerne ao entendimento dos relacionamentos interpessoais torna-se fundamental. Estudar a amizade sob a luz do que é produzido pela imprensa pode ajudar a entender seu significado para as pessoas.

Destaca-se que a pesquisa aqui apresentada faz parte de um projeto que teve o propósito de 
investigar de maneira mais ampla a amizade nos meios de comunicação de massa do Brasil. Este projeto, o qual constituiu como resultado final a tese de Doutorado em Psicologia da autora, incluiu ainda a observação do uso de apelos vinculados ao tema amizade em peças publicitárias e também a análise do tratamento dado ao tema amizade em um produto de teledramaturgia.

\section{Método}

A partir do objetivo desta pesquisa, elegeu-se 0 jornal Folha de S. Paulo como objeto de estudo, por ser o maior jornal do país em circulação, com média de vendagem diária na casa dos 300 mil exemplares. 0 crescimento anual registrado em 2010 foi por volta de $2,32 \%$, alcançando $7,16 \%$ do mercado de mídia impressa (segundo dados do Instituto Verificador de Circulação - IVC - que audita todos os produtos editoriais brasileiros). Vale destacar que, embora a intenção desta pesquisa seja fazer uma observação da amizade no contexto brasileiro, no que se refere ao jornal não existe um título que possa ser considerado nacional. Os jornais se caracterizam por seu regionalismo, e mesmo sendo a Folha de S. Paulo o jornal mais vendido no Brasil, ainda se precisa considerar o tratamento "paulista" que é dado ao seu conteúdo.

Para a coleta de dados, foi acessado 0 arquivo digital do jornal, que contém todas as matérias produzidas ao longo da história do periódico. Através do mecanismo de busca do site, é possível um acesso rápido a todo material que possa gerar algum tipo de interesse para o leitor, e foi esse procedimento que oportunizou a montagem da amostra. Assim, foram procuradas no arquivo as matérias que continham a expressão "amizade", tanto no título quanto no corpo do texto, bem como a sua variação de número. Considerou-se o tempo cronológico compreendido entre os anos de 2008 e 2010, e todas as matérias localizadas foram catalogadas para compor a amostra.

Assim, foram selecionadas 1695 matérias, e nelas, a palavra "amizade" foi utilizada 1862 vezes. Em 28 matérias, compôs o título. Todo o material coletado foi organizado e analisado a partir de um formulário de observação.

Como este estudo se propôs a investigar matérias jornalísticas, considerou-se a análise de conteúdo conforme proposta de Bardin (1977) como 0 recurso metodológico mais indicado, em função de permitir uma abordagem que vai além do aparentemente visível nas notícias e chamadas das reportagens. A grande projeção dessa forma de investigação no início do século 20 se deveu à divulgação dos estudos realizados na Universidade de Columbia, nos Estados Unidos, exatamente a partir da análise de conteúdo de materiais extraídos da imprensa norte-americana (CAREGNATO \& MUTTI, 2006). A partir de então, passou-se a associar positivamente a análise de conteúdo ao tratamento de matérias jornalísticas (AMORIM, 2008). 
Três etapas foram seguidas para a realização da análise dos dados coletados. Com as informações descritas através do formulário, foi feita uma pré-análise (1), considerando a importância de se obter uma visão geral dos dados coletados. A partir de então, realizou-se a exploração do material (2), quando foram definidas as categorias de observação de modo a permitir a combinação dos dados que se aproximavam e a discussão dos itens que abarcavam 0 interesse de pesquisa aqui expresso. A última etapa (3) contemplou a interpretação, 0 tratamento dos dados e a elaboração da discussão final, integrando os aspectos teóricos discutidos na abertura deste artigo e os dados que foram obtidos com a análise das matérias.

\section{Resultados}

A análise de conteúdo permite ao pesquisador observar uma palavra, analisando seu sentido nos textos em que aparece e a dimensão que ocupa na construção de uma mensagem. Consideramse ainda, em seus procedimentos, outros elementos linguísticos, tais como as imagens e as repetições. Através dela, é possível criar inferências a respeito de determinado assunto. Em se tratando da presente pesquisa, de caráter exploratório, pretendeu-se interpretar a utilização da palavra "amizade" no contexto editorial brasileiro. Assim, as 1862 ocorrências nas 1695 matérias jornalísticas da Folha de S. Paulo foram analisadas, organizadas, interpretadas e agrupadas por algum grau de similaridade, formando, então, 11 categorias que serão descritas a seguir.

A categoria "Produtos culturais" apresentou o maior número de ocorrências da palavra "amizade" e abarcou uma série de menções a produtos como filmes, livros, programas televisivos, músicas, peças teatrais e videogame. Em se tratando desse contexto, foram encontradas 721 utilizações da palavra amizade, e esse número elevado pode ser facilmente justificado quando se observa 0 alto índice de repetições dentro dessa categoria, como, por exemplo, as diversas vezes que um determinado filme foi citado enquanto esteve em cartaz. De modo geral, a palavra "amizade" foi empregada nos títulos desses produtos ou apareceu em suas sinopses, representando tema ou parte de seu enredo.

A categoria "Histórias de vidas" contou com 411 usos da palavra amizade nas matérias jornalísticas da Folha de S. Paulo. Nela, foram reunidos os textos que destacaram aspectos cotidianos de pessoas reais, incluindo episódios vividos; realizações conjuntas; associação para a prática de delitos; aproximação entre pessoas após episódio violento; e a amizade envolvendo a vida de atletas, personalidades de destaque na mídia, profissionais do mercado de trabalho, figuras históricas, religiosos e vizinhos.

A terceira categoria com maior número de reportagens catalogadas reuniu a utilização da palavra amizade em situações envolvendo 
"atuação política". 0s textos analisados nessa categoria apresentaram a característica de trazerem muitas falas e declarações dos próprios políticos, sendo, na maioria das vezes, escritos em $1^{a}$ pessoa do singular. Entre os 202 usos da palavra amizade, destacaram-se, com o maior número de menções, as reportagens que, de algum modo, comentaram sobre redes de relacionamentos, com a indicação que um determinado político era amigo de outro, e as principais ênfases foram: amizades construídas ao longo de um mandato; amizade muito antiga na cena política; e amizade entre presidentes de diferentes países. Também foi possível observar entre as reportagens selecionadas que a palavra amizade foi usada para expressar um sistema de favorecimento no meio político.

A categoria "Horóscopo" foi a única em toda a pesquisa formada exclusivamente a partir de uma seção da Folha de S. Paulo. Em três anos de observação das matérias desse jornal, foram encontradas 180 utilizações da palavra amizade como parte dos textos dos horóscopos, o que corresponde a aproximadamente $10 \%$ de toda a amostra. Em geral, as mensagens analisadas eram curtas e diretas, visto ser o horóscopo uma forma de abordagem diária em que 0 texto registra um comando para ser seguido no dia, portanto, com validade limitada. Três grandes ênfases foram percebidas nos textos: respeito à valorização de aspectos positivos da amizade, como a indicação de ser um bom dia para fazer amigos ou investir na busca por uma nova relação; aparente dualidade entre amizade e romance e dicas instrumentais para manutenção da amizade.

"Países e povos" reuniu uma dimensão de amizade internacional, com indicação de relações entre países e seus respectivos povos. As 105 matérias selecionadas apresentaram, de maneira geral, valorização de aspectos positivos advindos de uma relação de amizade, como bom convívio entre as nações, relações comerciais fortalecidas e clima amistoso entre os povos. A expressão "diplomacia da amizade" foi usada em alguns textos para designar o ideal de proximidade e cooperação entre os países. A principal ênfase da utilização da palavra amizade nessas matérias foi fazer referência a um país ser amigo de outro.

\section{A categoria "Expressões" reuniu as 74 matérias} em que foi possível observar esse aspecto sentimental conferido à palavra amizade sob diversas formas de expressão: mensagens endereçadas a amigos; gírias; jogos e brincadeiras; ditos populares; gestos; e considerações sobre 0 tema em textos religiosos, poéticos e filosóficos.

"Relações interpessoais" foi a categoria criada para reunir os 56 textos jornalísticos em que a palavra amizade foi usada para discutir relações interpessoais. Da amostra, 12 matérias contextualizaram a amizade no âmbito familiar, mas o modo de relacionamento mais discutido nas matérias em que a palavra amizade foi inserida nos textos foi o envolvimento romântico. Em 31 matérias, os leitores foram convidados a, 
de alguma maneira, associar essas duas formas de relação, seja refletindo sobre ser possível confundir amor e amizade ou avaliando a viabilidade de existir sexo entre amigos. Algumas ênfases foram: amigos que viraram amantes; amantes que deixaram a paixão "esfriar" e se tornaram amigos; a importância da amizade entre parceiros sexuais; e negativa de envolvimento amoroso, situando a relação entre duas pessoas apenas no campo da amizade.

A categoria "Figuras não humanas" foi formada por 52 matérias que apresentaram a ideia da amizade associada a objetos, animais e marcas. De modo geral, foram percebidos dois contextos para que essas figuras fossem associadas à amizade: meio ou fim. Como meio, foram indicados objetos que foram qualificados como indutores ou facilitadores da amizade. Como fim, foram encontrados relatos de objetos, atividades e animais com os quais as pessoas tinham amizade. Também mencionou-se a possibilidade de as pessoas criarem laços de amizade com marcas. A grande ênfase dessa categoria enquanto número de menções localizou-se na associação entre objetos e amizade, no sentido da promoção de vínculos.

Já a categoria "Lugares" foi formada a partir da seleção de todas as matérias em que a palavra amizade foi usada para se referir a um lugar. Em 30 menções, foram citados nove lugares no Brasil e no mundo em cujos nomes essa forma de relacionamento foi registrada. A escolha da palavra amizade para representar esses lugares pareceu indicar uma intenção de valorizar aspectos interculturais e internacionais. Entre todos os locais no Brasil e no mundo, o que apresentou maior índice de repetição foi a Ponte da Amizade (21 menções), a qual apareceu muito associada a notícias postadas no caderno policial em função de ser um cenário repetidamente comentado por episódios de contravenção e contrabando. As fotos que apareceram registrando as reportagens desta categoria tiveram relação com o fato que estava sendo noticiado ou mostraram simplesmente uma imagem do local. As repetições não foram significativas nessa categoria.

"Aspectos demográficos" reuniu os 20 textos que relacionaram algum aspecto demográfico à compreensão da amizade. De início, é importante destacar que as matérias selecionadas não traziam a amizade como 0 tema central, mas de algum modo, em seus contextos, essa discussão pôde ser percebida. Dois focos foram registrados: a descrição de comportamentos tipicamente masculinos e femininos na constituição da amizade (aspecto demográfico relacionado ao papel sexual) e a questão da idade influenciando as amizades, especialmente aparecendo na discussão a amizade entre crianças e entre jovens. A amizade entre mulheres recebeu o destaque de cinco matérias; a amizade típica da juventude foi descrita em $50 \%$ dos textos, e duas matérias descreveram a vinculação entre crianças. 
Por fim, foram selecionadas para a categoria "Eventos" as 11 matérias que usaram a palavra amizade relacionada à realização de algum acontecimento. Especialmente duas ênfases podem ser destacadas: eventos que receberam a palavra amizade em seus nomes e os que foram criados para promoção da amizade especificamente direcionados para o público jovem.

\section{Discussão}

Este trabalho investigou como a amizade se insere no cotidiano dos brasileiros, utilizando como objeto de estudo as matérias jornalísticas publicadas entre 2008 e 2010 no jornal de maior circulação do país. Nesse sentido, três destaques puderam ser observados, e essa discussão pretende articular os dados encontrados a outros estudos que também investigaram o tema amizade.

Em primeiro lugar, é preciso considerar a conotação que revestiu o assunto na maior parte das abordagens. A palavra amizade apareceu em nomes de monumentos que celebram a união e a fraternidade entre os povos. Eventos são organizados com o objetivo de promover integração. A amizade foi descrita por artistas, atletas, políticos, jornalistas, celebridades instantâneas ou anônimos, principalmente como uma forma de relacionamento que proporciona emoções positivas, realizações e promoção de bem-estar. Conforme as matérias, a amizade melhora 0 desempenho individual e traz maior satisfação pessoal. Ainda em cenários tipicamente competitivos - como as arenas esportivas ou as disputas eleitorais, por exemplo -, os registros de valorização da amizade superaram menções a conflitos e desavenças, que também foram citados, porém com menor destaque.

Muitos estudos também descrevem essa ênfase em conotações positivas (ARGYLE \& HENDERSON, 1985; BELL, 1981; KIPPER, 2003 apenas para citar alguns) e associam amizade à lealdade, à tolerância, à aceitação, à compreensão, à generosidade e ao apoio, entre outros. Segundo Argyle (2001), os relacionamentos são fatores primordiais para a felicidade e a saúde física e mental. Berscheid e Regan (2005) também valorizam o papel fundamental da amizade na promoção do bem-estar e da saúde.

Outro destaque importante que as matérias selecionadas deram ao tema foi a associação da amizade a benefícios advindos exclusivamente em virtude dessa forma de relação. Muitos dos textos mostraram que ter um amigo significa ter uma vantagem especial sobre as outras pessoas, seja, por exemplo, em uma indicação para vaga de emprego, na obtenção de convites para festas ou até pela isenção de responsabilidade em situações criminosas. 0 contexto no qual pôde ser percebida a maior ênfase dessa associação entre amizade e benefícios foi o político, e a categoria que reuniu esses textos descreveu situações de apadrinhamento e favorecimento que até geraram a criação de uma expressão verbal exclusiva para a situação: 0 vício da amizade. 
Holanda (1987), ao estudar a sociedade brasileira desde seu processo civilizatório, discute que as relações sociais no Brasil são revestidas por uma roupagem de cordialidade que serve para conquistar o outro e torná-lo amigo. Esse processo, essencialmente político, culmina com o surgimento de uma típica forma de amizade à brasileira, que privilegia 0 amigo em detrimento dos demais, mesmo quando o tal amigo em questão não tem razão ou está envolvido em episódios de ilegalidade. DaMatta (2003) completa essa ideia ao descrever que a sociedade brasileira é influenciada tanto por interesses da esfera pública quanto pelas amizades privadas. Outros estudos apontam para a tendência de privilegiar amigos no mercado de trabalho, destacando que, apesar de estruturas montadas para recrutamento e seleção de profissionais, o que vale, ainda, é a indicação (D'AVILA; REGIS e OLIVEIRA, 2010). Mesmo entre crianças, já existe o reconhecimento que um amigo é alguém com que se deve ser mais generoso do que se é com as demais pessoas

(VALE e ALENCAR, 2009).

Em terceiro lugar, é importante pontuar que as matérias analisadas associam, em vários aspectos, os relacionamentos típicos de amizade às relações românticas. Essa conexão apareceu desde títulos de filmes (Namoro ou amizade, por exemplo) a dicas instrumentais de horóscopos (como a sugestão de desenvolver a habilidade de discernir entre amor e amizade), passando por análises de diferenças demográficas na definição da amizade (homens têm dificuldade em diferenciar amizade de interesse sexual). Dois focos puderam ser observados nas matérias. 0 primeiro diz respeito a uma necessidade de escolha entre uma e outra forma de relação, como nos exemplos citados anteriormente. Nesse sentido, parece existir uma dualidade entre amizade e amor romântico, como se um fosse evolução do outro (ou vice-versa?), sendo importante aprender a não confundir os dois. A pergunta "é namoro ou amizade?" parece expor essa dualidade e, de tão cotidiana, passou a ser usada até em outros contextos, como 0 político, nesse caso para se referir a uma dúvida sobre filiação partidária. A expressão "amizade colorida" também foi usada em vários contextos, sendo que uma matéria especial discutiu 0 envolvimento entre amigos como uma forma de iniciação sexual para quase $20 \%$ dos jovens brasileiros. 0 segundo foco indica que a amizade é um sentimento complementar ao amor romântico, como algo que precisa ser desenvolvido entre parceiros que querem garantir a sobrevivência da relação em longo prazo.

Fehr (1996) elaborou uma revisão sobre conceitos de amizade e descreve ser essa uma forma de relacionamento interpessoal isenta de envolvimento sexual. Bell (1981) afirma que o envolvimento romântico altera profundamente a amizade, mudando o status da relação. Além disso, destaca que amizades com pessoas do mesmo sexo previnem quanto à possibilidade de um romance, sendo esse o motivo da preferência pela similaridade de gênero na escolha de um amigo. Por outro lado, Borges e Schor (2002) investigaram 
a iniciação sexual de jovens brasileiros e relataram que $10 \%$ da amostra teve sua primeira relação sexual com alguém reconhecido como amigo. Esse dado é mais tímido do que a pesquisa citada em uma das matérias da amostra, mas, de algum modo, registra um fenômeno.

Monsour (1992) também encontrou referências a envolvimento sexual entre amigos em uma pesquisa realizada com universitários norte-americanos. Aliás, a própria palavra usada para representar "namorado" na língua inglesa (boyfriend) parece de alguma maneira associar esse tipo de relacionamento amoroso ao envolvimento com um amigo (friend). Apesar de muitos autores diferenciarem essas duas formas de relação, Duck e Perlman (1985) alertam para o dinamismo das relações interpessoais, destacando a capacidade das pessoas de reinventarem seus vínculos com os outros. Por fim, é importante destacar que, dentro da grande área da psicologia, estudiosos dedicados à psicanálise encontram fortes conexões entre amizade e relacionamento amoroso (MUÑOZ, 2010), chegando a descrever que a maior diferença entre os dois reside na questão da reciprocidade (TOURNIER, 1986). Para existir amizade, é preciso reconhecimento mútuo, enquanto que no amor romântico esse sentimento não é obrigatório, pois nem sempre 0 envolvimento se concretiza.

Essas três associações bastante repetidas nas matérias jornalísticas permitem pontuar uma tendência de tratar o tema amizade no Brasil como uma forma de relacionamento desejável, 0 qual traz benefícios para os participantes da rede, que pode derivar para um envolvimento romântico e é fundamental para a relação entre casais e famílias. Nesse sentido, a amizade é também tratada como uma qualificação de outros tipos de relacionamento, passando a palavra "amigo", de sua natural condição de substantivo, a uma atuação na forma de adjetivo, complementando, por exemplo, os papéis sociais de pai, marido, irmão (o desejável é ser pai-amigo, maridoamigo, irmão-amigo). Para alguns pesquisadores, essa relação é positiva, por proporcionar experiências de exercício de fraternidade e por não ceder espaço, na relação entre os amigos, para episódios de dominação (KEHL, 2000). Outros pesquisadores discutem o perigo de vincular a figura do amigo a esses contextos de família e parentesco, sob pena de forçar uma homogeneidade nada natural entre os membros da rede e gerar, com isso, situações de intolerância e discriminação (GOMES \& SILVA JÚNIOR, 2008; DERRIDA, 1997).

\section{A tendência jornalística de revestir 0 tema} nos sentidos descritos anteriormente pôde ser percebida também nos títulos das matérias analisadas. Como observado na descrição metodológica, entre os 1.892 textos que compuseram a amostra, 28 deles apresentaram a palavra amizade compondo o título. Em um tratado clássico na área de jornalismo, Douglas (1966) afirma que muitos leitores fazem sua leitura de jornal apenas através dos títulos. Pereira Júnior (2006) completa essa ideia ao 
declarar que o título é a parte da matéria que grita. 0 Manual de Redação da Folha de S. Paulo orienta seus jornalistas a criarem títulos com poucas palavras, mas capazes de atrair a atenção do público (MANUAL... 2011). Assim sendo, fica fácil concluir que a escolha das palavras que irão compor o título de uma matéria jornalística não é uma decisão casual, mas, sim, registra uma intenção de despertar curiosidade e ao mesmo tempo informar.

Se a partir da análise de todos os textos da amostra foram formadas 11 categorias, é interessante notar que as matérias cujos títulos também apresentaram a palavra amizade ficaram restritas a cinco dessas categorias, exatamente as que refletiram com mais ênfase os três destaques apresentados: conotação positiva, benefícios/ privilégios e envolvimento amoroso, conforme poderá ser observado a seguir.

Dos 28 títulos, dez registraram sinopses de filmes, livros (um deles foi Sexo e amizade) e peças teatrais; oito focaram temas políticos, com ênfase total na apresentação de privilégios concedidos por figuras públicas aos seus amigos; cinco textos foram incorporados à categoria "Histórias de vidas" e destacaram tanto aspectos positivos das relações com amigos quanto a concessão de privilégios a alguém (como a manchete que citou um atleta que "entregou" a vitória para 0 time do amigo); três títulos comentaram sobre 0 crescimento das amizades mediadas por tecnologia; e dois deram ênfase em relacionamentos, um com vizinhos e 0 outro destacou sexo entre amigos.

Finalmente, algumas reflexões precisam ser feitas. A primeira delas diz respeito aos contextos. Como expressão cotidiana, os jornais registram os acontecimentos factuais. Assim, é natural observar que a exploração do tema amizade no noticiário esteve amplamente vinculada a esses acontecimentos, como matérias que aproveitaram um escândalo político para descrever situações de privilégios entre autoridades ou crimes com grande repercussão, que expuseram amigos como vítimas. Analisando o aspecto contextual, fica fácil concluir que o tema foi tratado com relativa similaridade ao longo de cada ano pesquisado, e que os maiores destaques em torno de algumas categorias específicas se deveram exatamente a acontecimentos factuais. Alguns exemplos podem ser descritos. 0 ano de 2010 aparece com aproximadamente 150 mais matérias compondo a amostra do que os anos anteriores, mas é fundamental lembrar que apenas o título do filme Ponyo, uma amizade que veio do mar, exibido nos cinemas naquele ano, foi responsável por 194 utilizações da palavra amizade. A categoria "Política" teve maior ênfase nos anos eleitorais. Menções a amigos envolvidos em episódios violentos tiveram destaque no ano em que os casos envolvendo a menina Isabela (assassinada por seus pais) e a jovem Eloá (assassinada pelo namorado) ganharam as principais manchetes do jornal. 0 ano do 
centenário da imigração japonesa no Brasil também rendeu um incremento no número de matérias que destacaram amizade entre países. Também é importante pontuar que as pessoas registradas nas matérias eram, principalmente, personalidades de destaque social e com reconhecimento público.

Assim como houve relativo equilíbrio na distribuição das matérias ao longo dos anos, também se percebeu uma distribuição natural de textos em torno das diversas editorias do jornal. A palavra amizade esteve presente em páginas policiais, no caderno de Cultura, em crônicas, na editoria de política, nas cartas do leitor, nas entrevistas com celebridades, no destaque do esporte e em praticamente todos os espaços disponíveis no noticiário. 0 índice de repetição da palavra amizade em uma mesma matéria foi baixo, uma média de 1,09, considerando as 1862 menções que ocorreram em 1695 matérias. 0 texto com o maior número de repetições foi exatamente a única matéria da amostra que teve como foco principal a discussão do tema amizade, tratado como uma forma de relacionamento que une pessoas de todas as idades, classes sociais e estilos de vida. Todas as demais matérias abordaram a amizade como um fato inserido em um contexto. Isso faz pensar se a amizade no Brasil é algo que se vive, mas que não se discute.

É importante destacar ainda que a utilização de imagens para ilustrar as matérias privilegiou os acontecimentos, com ênfase nas pessoas citadas no texto ou no simples registro do fato em si.

Nas imagens em que foi possível perceber uma intenção editorial de registrar amizade entre as personalidades citadas na matéria, a proximidade física foi o principal recurso utilizado.

\section{Considerações Finais}

Este trabalho pretendeu analisar como a amizade se insere no cotidiano dos brasileiros, a partir do registro noticioso de um meio de comunicação de massa. Como os produtos de mídia são tão amplamente difundidos no Brasil, fazendo parte da rotina de informação e entretenimento de muitos brasileiros - muitas vezes como única fonte de conexão com o mundo -, é importante considerar esse um segmento fundamental para a realização de diversas pesquisas no campo das ciências sociais, especialmente no que tange à construção e manutenção de relações. As duas áreas de estudo (a comunicação e a ciência dos relacionamentos interpessoais) apresentam diversos pontos em comum, e estreitá-los pode ser um passo importante para a construção de uma sociedade mais plena e hábil na capacidade de interagir e se relacionar.

Olhar a amizade como um fenômeno digno de ser estudado pela ciência é algo novo na história. Por mais que se tenha acostumado a viver a amizade e também a se pensar filosoficamente sobre ela desde tempos longínquos, não foi apenas a partir da segunda metade do século 20 que a Academia incorporou os relacionamentos interpessoais como 
objeto de estudo. Desde então, a vinculação íntima de duas pessoas que, a princípio, não são parentes e nem estão envolvidas sexualmente passou a ser discutida à luz de teorias formuladas a partir dessas mesmas experiências empíricas.

Como produto cultural tão presente no cotidiano dos brasileiros, é essencial estabelecer uma articulação mais estreita entre a mídia e os estudos de relacionamento interpessoal. Percebese que são esses dois elementos centrais na vida cotidiana, e entender suas conexões pode ajudar a interpretar em que base as pessoas constroem suas relações e a que tipo de influência estão expostas. Do mesmo modo que já se consegue mensurar o quanto uma mensagem comercial converte-se em comportamento de consumo, seria importante observar a relação dialética que se estabelece entre exposição não só da amizade, mas também de outras formas de relacionamento interpessoal. Até que ponto as pessoas usam as representações apresentadas pela mídia para construir suas relações reais e próximas permanece como um desafio de identificação e descoberta para pesquisas futuras.

\section{Referências}

AMORIM, T. A. Nanotecnologia na imprensa: análise de conteúdo do jornal Folha de São Paulo. Revista Eletrônica dos Pós-Graduandos em Sociologia Política da UFSC, Vol. 4 n. 2 (2), 2008.

\section{ARGYLE, M. \& HENDERSON, M. The rules of} relationships. In S. Duck \& D. Perlman (Eds.), Understanding personal relationships (pp. 63-84). London: Sage, 1985.
ARGYLE, M. The Psychology of Happiness. New York: Taylor e Francis, 2001.

BARDIN, L. Análise de Conteúdo. Lisboa: Edições $70,1977$.

BELL, R. Worlds of friendship. Beverly Hills: Sage, 1981.

BERSCHEID, E. \& REGAN, P. The psychology of interpersonal relationships. Upper Saddle River: Pearson, 2005.

BORGES, A. L. V. e SCHOR, N. Início da vida sexual na adolescência e relações de gênero: um estudo transversal em São Paulo, Brasil. Cad. Saúde Pública, vol.21, n.2, pp. 499-507, 2002.

CAREGNATO, R. C. e MUTTI, R. Pesquisa qualitativa: análise de discurso versus análise de conteúdo. Revista Contexto. Florianópolis, out-dez, 15(4), 679$684,2006$.

CASALI, C. Dois femininos, dois discursos: 0 tratamento da tensão entre o amor e a amizade nas revistas Todateen e Malu. UNIrevista - v.1, n. 3, 01-10, 2006.

COUTO, W. G. S. e MENANDRO, P. R. M. Imagens da adolescência na Revista Capricho. Revista Brasileira de Desenvolvimento Humano; 3 (1): 63-78, 2003.

DAMATTA, R. Em torno dos amigos e da amizade. In Leituras compartilhadas. Ano 3, n. 2. Fascículo 10. Rio de Janeiro: Leia Brasil, 2003.

D’AVILA, G. C.; Regis, H. P. e Oliveira, L. M. B. Redes sociais e indicações para processos de recrutamento e seleção: uma análise pela perspectiva dos candidatos. Revista Psicologia: Organizações e Trabalho. Florianópolis, v. 10, n. 1, 2010.

DERRIDA, J. Politics of friendship. New York: Verso, 1997.

DOUGLAS, J. Jornalismo: A técnica do título. Rio de Janeiro, Agir, 1966. 
DUCK, S. \& PERLMAN, D. (Eds.). Understanding personal relationships. London: Sage, 1985.

ERBOLATO, R. Contatos sociais: relações de amizade em três momentos da vida adulta. Tese de Doutorado Não-Publicada, Programa de Pós-Graduação do Instituto de Psicologia e Fonoaudiologia, Pontifícia Universidade Católica de Campinas, Campinas, 2001.

FEHR, B. Friendship processes. London: Sage., 1996.

GARCIA, A. Relacionamento interpessoal - uma área de investigação. In: Garcia, A. (Orgs.).

Relacionamento Interpessoal: olhares diversos. Vitória: UFES, 2005.

GOMES, L. G. N. \& SILVA JÚNIOR, N. Implicações políticas da semântica familialista nos discursos de amizade contemporâneos. Psicologia em Estudo, 13(2), 267-275, 2008.

HOLANDA, S. B. Raízes do Brasil. 19a edição. Rio de Janeiro: José Olympio, 1987.

KEHL, M. R. Existe a função fraterna? Em M. R. Kehl (Org.), Função fraterna (pp. 31-47). Rio de Janeiro: Relume Dumará., 2000.

KIPPER, A. Sobre a amizade: relações de trabalho e bem-estar subjetivo. Dissertação de Mestrado NãoPublicada, Programa de Pós-Graduação em Psicologia do Desenvolvimento, Universidade Federal do Rio Grande do Sul, Porto Alegre, 2003.

MANUAL de Redação da Folha de São Paulo. São Paulo: Folha de São Paulo, Publifolha, 2011.

MARTINS, A. L. Revistas em revista: imprensa e práticas culturais em tempos de República. São Paulo: Editora Universidade de São Paulo (FAPESP), 2008.

MONSOUR, M. Meanings of intimacy in cross- and same-sex friendships. Journal of Social and Personal Relationships, 9(2), 277-295, 1992.

MUÑOZ, N. M. Do amor à amizade na psicose: contribuições da psicanálise ao campo da saúde mental. Revista Latinoamericana de Psicopatologia Fundamental, 13, 87-101, 2010.

PEREIRA JÚNIOR, L. A vida com a TV - o poder da televisão no cotidiano. São Paulo: Editora SENAC, 2006.

SCHWERTNER, S. F. Laços de amizade. Modos de relacionamento jovem em tempos de conectividade digital. Tese de Doutorado. Programa de Pósgraduação em Educação, Universidade Federal do Rio Grande do Sul. Porto Alegre, Rio Grande do Sul, 2010.

TOURNIER, M. Petites proses. Paris: Gallimard, 1986.

VALE, L. G. e ALENCAR, H. M. Generosidade para com Amigo, Desconhecido e Inimigo: Juízos Morais de Crianças e Adolescentes. Interação em Psicologia, 13(2), p. 299-310, 2009. 
Friendship on newsmakers: interpersonal relationships in the Brazilian press

\section{Amistad en las noticias: las relaciones interpersonales en la prensa brasileña}

\section{Abstract}

This study examined how friendship fits into the daily lives of Brazilians from the observation of stories that were aired in a newspaper of general circulation in the country between 2008 and 2010. The sample consisted of 1,695 news stories that had the word friendship as part of their titles and / or texts. The analysis identified 11 categories in which the materials were classified and the results indicated that friendship is seen as a way relationship provides positive emotions, personal achievements, well-being, improves individual performance brings greater personal satisfaction and ensures the provision of benefits mutual. The materials analyzed were also associated, in many respects, typical relationships of friendship to romantic relationships.

\section{Keywords}

News. Media. Interpersonal relationships.

Friendship. Newspaper articles.

\section{Resumen}

Este estudio examinó cómo la amistad encaja en la vida cotidiana de los brasileños a partir de la observación de las historias que se ventilaron en un periódico de circulación general en el país entre 2008 y 2010. La muestra está formada por 1.695 noticias que tuvieron la palabra amistad como parte de sus títulos y / 0 textos. El análisis identificó 11 categorías en que se clasifican los materiales y los resultados indicaron que la amistad es visto como una relación de doble vía proporciona emociones positivas, logros personales, el bienestar, mejora el rendimiento del individuo aporta mayor satisfacción personal y garantiza la prestación de los beneficios mutua. Los materiales analizados también se asociaron, en muchos aspectos, las relaciones típicas de la amistad de las relaciones románticas.

\section{Palabras-Clave}

Noticias. Media. Las relaciones interpersonales. Amistad. Los artículos de prensa. 


\section{Expediente}

A revista E-Compós é a publicação científica em formato eletrônico da Associação Nacional dos Programas de Pós-Graduação em Comunicação (Compós). Lançada em 2004, tem como principal finalidade difundir a produção acadêmica de pesquisadores da área de Comunicação, inseridos em instituições do Brasil e do exterior.

\section{E-COMPÓS I www.e-compos.org.br I E-ISSN 1808-2599}

Revista da Associação Nacional dos Programas

de Pós-Graduação em Comunicacão.

Brasília, v.17, n.3, set./dez. 2014

A identificação das edições, a partir de 2008

passa a ser volume anual com três números.

\section{CONSELHO EDITORIAL}

Afonso Albuquerque, Universidade Federal Fluminense, Brasil Alberto Carlos Augusto Klein, Universidade Estadual de Londrina, Brasil Alex Fernando Teixeira Primo, Universidade Federal do Rio Grande do Sul, Brasil Ana Carolina Damboriarena Escosteguy, Pontifícia Universidade Católica do Rio Grande do Sul, Brasi

Ana Gruszynski, Universidade Federal do Rio Grande do Sul, Brasil Ana Silvia Lopes Davi Médola, Universidade Estadual Paulista, Brasil André Luiz Martins Lemos, Universidade Federal da Bahia, Brasi Ângela Freire Prysthon, Universidade Federal de Pernambuco, Brasi Antônio Fausto Neto, Universidade do Vale do Rio dos Sinos, Brasil Antonio Carlos Hohlfeldt, Pontifícia Universidade Católica do Rio Grande do Sul, Brasil Antonio Roberto Chiachiri Filho, Faculdade Cásper Líbero, Brasi Arlindo Ribeiro Machado, Universidade de São Paulo, Brasil Arthur Autran Franco de Sá Neto, Universidade Federal de São Carlos, Brasil Benjamim Picado, Universidade Federal Fluminense, Brasil César Geraldo Guimarães, Universidade Federal de Minas Gerais, Brasil Cristiane Freitas Gutfreind, Pontifícia Universidade Católica do Rio Grande do Sul, Brasil Denilson Lopes, Universidade Federal do Rio de Janeiro, Brasil Denize Correa Araujo, Universidade Tuiuti do Paraná, Brasil Edilson Cazeloto, Universidade Paulista, Brasil

Eduardo Vicente, Universidade de São Paulo, Brasil

Eneus Trindade, Universidade de São Paulo, Brasil

Erick Felinto de Oliveira, Universidade do Estado do Rio de Janeiro, Brasil Florence Dravet, Universidade Católica de Brasilia, Brasil

Gelson Santana, Universidade Anhembi/Morumbi, Brasi Gilson Vieira Monteiro, Universidade Federal do Amazonas, Brasil Gislene da Silva, Universidade Federal de Santa Catarina, Brasil Guillermo Orozco Gómez, Universidad de Guadalajara, México Gustavo Daudt Fischer, Universidade do Vale do Rio dos Sinos, Brasil Hector Ospina, Universidad de Manizales, Colômbia Herom Vargas, Universidade Municipal de São Caetano do Sul, Brasil leda Tucherman, Universidade Federal do Rio de Janeiro, Brasil Inês Vitorino, Universidade Federal do Ceará, Brasil Janice Caiafa, Universidade Federal do Rio de Janeiro, Brasil Jay David Bolter, Georgia Institute of Technology, Estados Unidos João Freire Filho, Universidade Federal do Rio de Janeiro, Brasil John DH Downing, University of Texas at Austin, Estados Unidos Jeder Silveira Janotti Junior, Universidade Federal de Pernambuco, Brasi

José Afonso da Silva Junior, Universidade Federal de Pernambuco, Brasil José Carlos Rodrigues, Pontifícia Universidade Católica do Rio de Janeiro, Brasil José Luiz Aidar Prado, Pontifícia Universidade Católica de São Paulo, Brasil José Luiz Warren Jardim Gomes Braga, Universidade do Vale do Rio dos Sinos, Brasil Juremir Machado da Silva, Pontifícia Universidade Católica do Rio Grande do Sul, Brasil Laan Mendes Barros, Universidade Metodista de São Paulo, Brasi Lance Strate, Fordham University, USA, Estados Unidos Lorraine Leu, University of Bristol, Grã-Bretanha Lucia Leão, Pontifícia Universidade Católica de São Paulo, Brasil Luciana Panke, Universidade Federal do Paraná, Brasil Luiz Claudio Martino, Universidade de Brasília, Brasil Malena Segura Contrera, Universidade Paulista, Brasil Márcio de Vasconcellos Serelle, Pontifícia Universidade Católica de Minas Gerais, Brasil Maria Aparecida Baccega, Universidade de São Paulo e Escola Superior de Propaganda e Marketing, Brasi Maria das Graças Pinto Coelho, Universidade Federal do Rio Grande do Norte, Brasil Maria Immacolata Vassallo de Lopes, Universidade de São Paulo, Brasil Maria Luiza Martins de Mendonça, Universidade Federal de Goiás, Brasil Mauro de Souza Ventura, Universidade Estadual Paulista, Brasil Mauro Pereira Porto, Tulane University, Estados Unidos Nilda Aparecida Jacks, Universidade Federal do Rio Grande do Sul, Brasil Paulo Roberto Gibaldi Vaz, Universidade Federal do Rio de Janeiro, Brasil Potiguara Mendes Silveira Jr, Universidade Federal de Juiz de Fora, Brasil Renato Cordeiro Gomes, Pontifícia Universidade Católica do Rio de Janeiro, Brasil Robert K Logan, University of Toronto, Canadá

Ronaldo George Helal, Universidade do Estado do Rio de Janeiro, Brasil Rosana de Lima Soares, Universidade de São Paulo, Brasi Rose Melo Rocha, Escola Superior de Propaganda e Marketing, Brasil Rossana Reguillo, Instituto de Estudos Superiores do Ocidente, México Rousiley Celi Moreira Maia, Universidade Federal de Minas Gerais, Brasi Sebastião Carlos de Morais Squirra, Universidade Metodista de São Paulo, Brasil Sebastião Guilherme Albano da Costa, Universidade Federal do Rio Grande do Norte, Brasil

Simone Maria Andrade Pereira de Sá, Universidade Federal Fluminense, Brasi Suzete Venturelli, Universidade de Brasília, Brasil

Tiago Quiroga Fausto Neto, Universidade de Brasília, Brasil

Valerio Fuenzalida Fernández, Puc-Chile, Chile

Veneza Mayora Ronsini, Universidade Federal de Santa Maria, Brasi Vera Regina Veiga França, Universidade Federal de Minas Gerais, Brasil

\section{COMISSÃO EDITORIAL}

Cristiane Freitas Gutfreind I Pontifícia Universidade Católica do Rio Grande do Sul, Brasil Irene Machado I Universidade de São Paulo, Brasil

Jorge Cardoso Filho I Universidade Federal do Recôncavo da Bahia, Brasil Universidade Federal da Bahia, Brasil

CONSULTORES AD HOC

Adriana Amaral, Universidade do Vale do Rio dos Sinos, Brasil

Alexandre Rocha da Silva, Universidade Federal do Rio Grande do Sul, Brasi

Arthur Ituassu, Pontifícia Universidade Católica do Rio de Janeiro, Brasil

Bruno Souza Leal, Universidade Federal de Minas Gerais, Brasil

Elizabeth Bastos Duarte, Universidade Federal de Santa Maria, Brasil

Francisco Paulo Jamil Marques, Universidade Federal do Ceará, Brasi

Maurício Lissovsky, Universidade Federal do Rio de Janeiro, Brasil

Suzana Kilpp, Universidade do Vale do Rio dos Sinos, Brasil

Vander Casaqui, Escola Superior de Propaganda e Marketing, Brasi

EDIÇ̃̃O DE TEXTO E RESUMOS I Press Revisão

SECRETÁRIA EXECUTIVA I Helena Stigger

EDITORAÇÃo ELETRÔNICA I Roka Estúdio
COMPÓS I www.compos.org.br

Associação Nacional dos Programas de Pós-Graduação em Comunicação

Presidente

Eduardo Morettin

Universidade de São Paulo, Brasil

eduardomorettin@usp.br

Vice-presidente

Inês Vitorino

Universidade Federal do Ceará, Brasil

ines@ufc.br

Secretária-Geral

Gislene da Silva

Universidade Federal de Santa Catarina, Brasil

gislenedasilva@gmail.com 